\title{
Reporte de caso de Síndrome de Marfán en Odontología
}

\section{A case report of Marfan Sindrome in Dentistry}

\author{
Mercado $\mathrm{SF}^{1}$, Caciva $\mathrm{RC}^{1}$, Morales $\mathrm{SJ}^{1}$. \\ ${ }^{1}$ Universidad Nacional de Córdoba, Facultad de Odontología, Departamento de Patología Bucal, Argentina
}

\begin{abstract}
Marfan syndrome is a genetic disease with an autosomal dominant inheritance pattern, which compromises the connective tissue in a systemic way, and with a high degree of clinical variability. The importance for the Odontoestomatologist lies in the fact that the growth and development of the jaws / teeth are in greater or lesser proportion in relation to the general skeletal growth. In this way, the correlation between individual line measurement, adenoid facies and subsequent oral examination are fundamental for presumptive diagnosis, not only in pediatric dentistry but also in general practice. It is noteworthy that the alterations of skin, muscles and joints give visible symptomatic manifestations to the simple presence of the patient. This article describes the clinical case of a female patient with this syndrome.
\end{abstract}

KEYWORDS: Marfan syndrome, clinical dentistry

\section{Resumen}

El síndrome de Marfán es una enfermedad genética con un patrón de herencia autosómico dominante, que compromete al tejido conectivo en forma sistémica, y con un alto grado de variabilidad clínica. La importancia para el Odontoestomatólogo reside en el hecho de que el crecimiento y desarrollo de los maxilares/dientes están en mayor o menor proporción en relación con el crecimiento esquelético general. De esta manera la correlación entre individuo longilíneo, facie adenoidea y el posterior examen bucal son fundamentales para el diagnóstico presuntivo, no sólo en odontopediatría sino también en la práctica general. Es de destacar, que las alteraciones de piel, músculos y articulaciones dan manifestaciones sintomáticas visibles a la simple presencia del enfermo. En este artículo se relata el caso clínico de un paciente de sexo femenino con este síndrome.

PALABRAS CLAVE: síndrome de Marfán, clínica odontológica

\section{Introducción}

El síndrome de Marfán es una enfermedad genética con un patrón de herencia autosómico dominante, que compromete al tejido conectivo en forma sistémica, y con un alto grado de variabilidad clínica. Las manifestaciones típicas son las que involucran los sistemas ocular, esquelético y cardiovascular. Las mutaciones del gen Fibrillin 1 (FNB1) pueden generar distintos fenotipos, desde características aisladas, hasta presentaciones neonatales graves y rápidamente progresivas que involucran múltiples órganos y sistemas. Si bien la miopía es la patología ocular más frecuente, la subluxación del cristalino (ectopia lentis) está presente en el 60\% de los individuos afectados y es la más característica del síndrome de Marfán. De todos modos, los afectados tienen riesgo aumentado de padecer desprendimiento de retina, cataratas y glaucoma. El sistema esquelético se caracteriza por sobre crecimiento óseo e hiperlaxitud articular. Las extremidades son es proporcionadamente largas con respecto al tamaño del tronco (dolicostenomelia) ${ }^{1-4}$.

$\mathrm{Si}$ tenemos en cuenta en realizar una correcta historia clínica y metodología odontoestomatológica: el síndrome de Marfán es un proceso mórbido, genético, que se describe en la niñez y en los adultos, caracterizándose con alteraciones óseas, cardiovasculares y bucales; observándose sus extremidades, dedos largos y finos, escoliosis. La importancia para el Odontoestomatólogo reside en el hecho de que el 
crecimiento y desarrollo de los maxilares/dientes están en mayor o menor proporción en relación con el crecimiento esquelético general. De esta manera la correlación entre individuo longilíneo, facie adenoideo y el posterior examen bucal son fundamentales para el diagnóstico presuntivo, no sólo en odontopediatría sino también en la práctica general. Es de destacar, que las alteraciones de piel, músculos y articulaciones dan manifestaciones sintomáticas visibles a la simple presencia del enfermo.

\section{Presentación del caso}

El paciente es de sexo femenino, de 24 años de edad, caucásica, con estudios terciarios y que, oriunda de la ciudad de Catamarca, talla: 1,83 mts, peso: $68 \mathrm{~kg}$, IMC: 20,3. Longilínea, aracnodactilia, dólico-estelomelia, actitud asténica. No bebe ni fuma. Presenta períodos menstruales normales. Tuvo un parto por cesárea sin complicaciones.

\section{Aspectos éticos}

El paciente ha firmado el consentimiento informado. En este estudio se han contemplado los delineamientos de la declaración médica de Helsinki y Nüremberg. Para esta investigación no se realizaron experimentos con seres humanos ni animales. Los autores declaran que en este artículo no aparecen datos de los pacientes.

\section{Motivo de consulta:}

La paciente concurre a consulta a la cátedra de Semiología de la Facultad de Odontología de la Universidad Nacional de Córdoba. Al momento de la consulta menciona que tiene sensibilidad de encía (uliodinea) generalizada y aumento de tamaño (macrulia) desde hace un año, y ha se le ha indicado un tratamiento con colutorio y cepillos para ortodoncia.

\section{Antecedentes hereditarios:}

La paciente relata que por parte de su madre su abuela era diabética y su abuelo presentaba complicaciones cardíacas. Mientras que por línea paterna, su abuelo falleció por cáncer de vejiga y su abuela tenía enfermedad renal y debía ser dializada. Por otra parte su madre padecía artritis reumatoide (Fig 1).

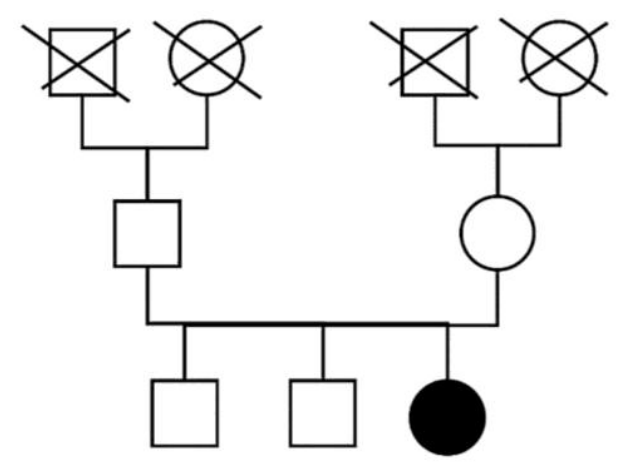

Figura 1. Árbol genealógico de la paciente

\section{Antecedentes médicos generales}

La paciente presentaba síntomas generales de de este síndrome Fig. 2

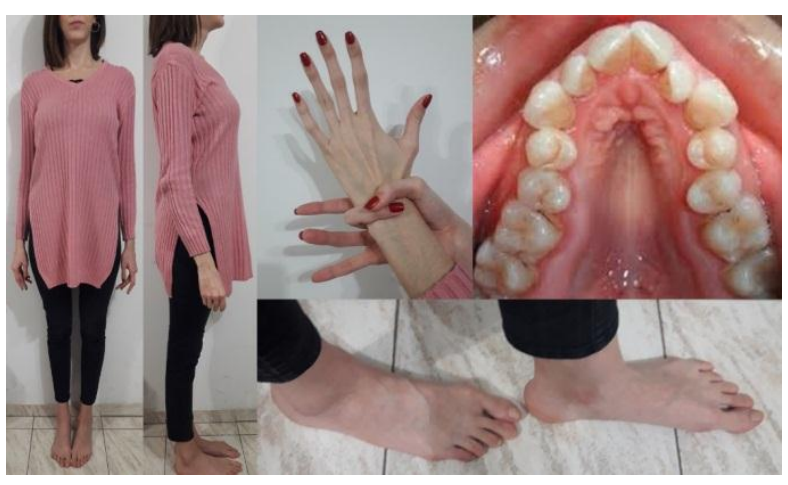

Figura 2. En la paciente se observan las características generales del síndrome de Marfán: sobrecrecimiento óseo e hiperlaxitud articular Las extremidades son es proporcionadamente largas con respecto al tamaño del tronco (dolicostenomelia).

Además su ficha médica registra otras características como rinitis alérgica, gastritis. Intervenciones quirúrgicas de rinoplastia e implantes mamarios en las cuales no se registraron complicaciones a la anestesia general. En relación a la cavidad bucal, la paciente, se encuentra al momento de la consulta bajo tratamiento ortodóntico.

Por otra parte ha sido diagnosticada, desde hace 13 años, de dilatación de aorta torácica ascendente (11 años de edad: 35/36 mm; actualmente: $43 \mathrm{~mm}$ en raíz aórtica), insuficiencia valvular aórtica, mitral y tricuspídea, pectum carinatum, escoliosis, paladar ojival, apiñamiento dentario, maloclusión, empaquetamiento de alimentos, facie dólicocefálica, cristalinos desplazados, miopía y 
astigmatismo (diagnosticada desde los 8 años de edad, usa anteojos). Debe realizar controles semestrales mamográficos por aumento mamario con prótesis. El médico tratante sugirió realizar controles con los siguientes estudios de valoración: evaluación cardiovascular clínica (examen físico, tensión arterial y espirometría) y con trazados e imágenes (electrocardiograma, ecocardiografía Doppler, telerradiografía de tórax, resonancia magnética con contraste para evaluar dilatación aórtica), valoración oftalmológica, valoración tocoginecológica (Mamografía de control semestral).

Medicación: Atenolol (betabloqueantes): a los 11 años $25 \mathrm{mg} /$ día; desde los 19 años $50 \mathrm{mg}$ /día. Antialérgicos sin corticoides (rinitis). Anticonceptivos orales. Indicaciones: dieta baja en sodio, actividad física aeróbica sin impacto. Evitar hábitos tóxicos.

\section{Tratamiento odontológico}

Según la valoración integral se indicó el tratamiento odontológico correspondiente con la participación de un equipo multidisciplinario, realizando un diagnóstico de certeza, ayudando a prevenir complicaciones y evitar la instalación de hábitos que perjudican su correcta fonación, alimentación, movimientos de cabeza y cuello, y aspecto estético.

Debido a la condición anatómica de su estructura palatina se instaló aparatología fija con expansores, con indicaciones previas y precisas desde el punto de vista periodontal, en su higiene bucodental con cepillos adecuados evitando la formación del biofilm, hilo dental y colutorios sin alcohol para evitar molesticas con brackets y arcos; de esa manera se obtuvo una exitosa respuesta, debido a la conducta saludable de la paciente logrando que los tejidos gingivales regresaran a tu tamaño, sin gingivorragia ni halitosis.

Sabemos que la inter y multidisciplina tienen relevancia para estos casos y especialmente para que los controles sean realizados por profesionales especializados en este tipo de afecciones, por ello, lo ideal es que el Odontoestomatólogo trabaje en equipo con el psicólogo, nutricionista, fonoaudiólogo, fisioterapeuta,otorrinolaringólogo; logrando así que la paciente aceptara el uso de la aparatología, mejorando su higiene, respiración, fonación; lo cual, aumentó su autoestima integrándose socialmente. Tener en cuenta que el criterio clínico es útil al momento de definir el diagnóstico favoreciendo una mejor calidad de vida.

\section{Discusión}

Los trastornos músculo-esqueléticos son los más importantes para el diagnóstico de la enfermedad y se encuentran con mayor frecuencia la presencia de talla alta con desproporción corporal a expensas del segmento inferior, escoliosis y aracnodactilia, unidos a los signos radiológicos que caracterizan las principales manifestaciones óseas.

Estos aspectos se deben tener en cuenta a la hora de realizar el diagnóstico, se precisa que las manifestaciones clínicas de este síndrome son muy variadas por su heterogeneidad genética y las alteraciones de las proporciones corporales, lo que hace sospechar la existencia de la enfermedad aun en ausencia de cardiopatía, o de manifestaciones oculares. ${ }^{\text {ii }}$

Algunos autores como Chevalier ${ }^{4}$ y otros proponen la valoración de estos enfermos por un equipo multidisciplinario que permita realizar un certero diagnóstico de manera que diferencie esta entidad de otros hábitos marfanoides y proporcione un seguimiento riguroso que ayude a prevenir las complicaciones.

Las personas con síndrome de Marfán son frecuentemente altas y ágiles y este fenotipo adecuado para la práctica de deportes y otras actividades de sobrecarga física, los vincula con frecuencia a tareas que aumentan su riesgo de disección aórtica y muerte súbita. Acorde con lo planteado en la Introducción y según lo recogido en la literatura médica internacional y nuestro caso clínico, señalamos la importancia de realizar un diagnóstico temprano y una orientación adecuada de los enfermos sobre el régimen de actividades que pueden llevar a cabo para lograr una mayor calidad y expectativa de vida ${ }^{1-4}$.

\section{Conclusiones}

En el $75 \%$ de los casos los afectados tienen un progenitor afectado y en el $25 \%$ son mutaciones de novo (mutación nueva, que no es heredada por los progenitores, sino que se presenta solamente en el afectado).Hoy sabemos que la interdisciplina es esencial para el abordaje de este tipo de patologías con afectación de múltiples órganos. Es ideal contar con un equipo que incluya genetista, psicólogo, ortopedista, oftalmólogo, cardiólogo, cardiocirujano, nutricionista y odontólogo. El interés de este cuadro radica en su posible presentación en forma de muerte súbita sin ningún tipo de clínica previa. El diagnóstico debe 
establecerse en la infancia o en la juventud y el seguimiento ha de ser multidisciplinario.

Conocer esta entidad es importante, tanto para los médicos y como odontólogos, tanto de adultos como pediátricos, y para los especialistas. Siempre se sugiere un abordaje multidisciplinario dado la afectación multi-orgánica. Es relevante tener en cuenta que los criterios clínicos son muy útiles al momento de definir el diagnóstico, pero son edad-dependientes.

De esta manera, la correlación entre la talla y posterior examen de la cavidad bucal son fundamentales no sólo en odontopediatría y ortodoncia, sino también en periodoncia, estomatología y cirugía. Esto significa que muchos pacientes reúnen algunos criterios, que sin embargo no alcanzan para definir la afectación, y, con el seguimiento longitudinal, se puede definir o descartar la enfermedad, a veces apoyándose en las técnicas de biología molecular. Lo básico y relevante es que, a la sola inspección del paciente tengamos presente su integridad psico-física en la seguridad y convencimiento de que fin del accionar de un profesional semiólogo no es el de diagnosticar y tratar una boca, sino diagnosticar y tratar un paciente enfermo en el que examinaremos especialmente la cavidad bucal con la sintomatología que motivó la consulta pero siempre considerándola integrada a toda la persona y el conocimiento no sólo de la biomecánica bucal sino también de los conocimientos básicos científicos de la psicología humana en el difícil tiempo de conllevar la enfermedad.

Finalmente, la evaluación conjunta entre el pediatra, el odontólogo, el endocrinólogo y el ortodoncista, es crucial para la vigilancia de los parámetros de crecimiento y desarrollo.

Los autores declaran que no existen conflictos potenciales de interés con respecto a la autoría y/o publicación de este artículo.

The authors declare no potential conflicts of interest with respect to the authorship and/or publication of this article.

\section{Referencias}

1. Radke RM, Baumgartner H. Diagnosis and treatment of Marfan syndrome: an update. Heart. 2014; 100(17):1382-91. doi: 10.1136/heartjnl-2013-304709.

2. Pyeritz, RE. Etiology and pathogenesis of the Marfan syndrome: current understanding. Ann Cardiothorac Surg. 2017; 6(6):595-598.
3. Gawinecka J, Schönrath F, von Eckardstein A. Acute aortic dissection: pathogenesis, risk factors and diagnosis. Swiss Med Wkly 2017; 147:w14489.

4. Chevallier B, Albert M, Boileau C, Chagnon S, Goldschild M, Jondeau et al. Value of multidisciplinary consultation in diagnosis and survival of Marfan syndrome. Press Med 1998; 27(28):1424-6.

Correspondencia a/Corresponding to: Dr. Silvia Mercado

Facultad de Odontología, Universidad Nacional de Córdoba Haya de La Torre s/n, Pabellón Argentina, Ciudad Universitaria, CP 5000, Córdoba-Argentina. Correo electrónico (e-mail): silvia.mercado@unc.edu.ar 
